\title{
Patterns of HIV Diagnosis Disclosure to Infected Children and Family Members: Data from a Paediatric Antiretroviral Program in South Africa
}

\author{
Sphiwe Madiba \\ School of Public Health, University of Limpopo, Medunsa Campus, Pretoria, South Africa. \\ Email: Sphiwe_madiba@embanet.com
}

Received July $8^{\text {th }}$, 2012; revised August $8^{\text {th }}$, 2012; accepted August $15^{\text {th }}, 2012$

\begin{abstract}
The study examined the patterns of disclosing the HIV diagnosis to infected children and family members, and determined the demographic characteristics associated with disclosure. Semi structured interviews were conducted with caregivers of HIV infected children aged 4 - 17 years receiving antiretroviral treatment (ART). A total of 149 caregivers were recruited from a paediatric HIV clinic of a district hospital in South Africa. Caregivers reported that 59 (39.6\%) children were told their HIV diagnosis, and majority $36(61 \%)$ were informed of the diagnosis by people other than their biological mothers. Older child age was a determining factor for HIV disclosure to children, 22 (37.2\%) learned of their HIV diagnosis between 11 and 16 years. The mean age of disclosed children was 10.6 years. Caregivers took about 3 years after the initial HIV diagnosis to disclose to children, while 143 (99.3\%) caregivers reported that disclosure to family members happened immediately after the child's HIV diagnosis. About 28 (31.5\%) non-disclosed caregivers planned to disclose to the child between 12 and 18 years, while $13(14.6 \%)$ were not sure about the ideal age to disclose to the child. The lack of consensus regarding the appropriate age for disclosure and the delayed age for future disclosure, suggest that despite increased access to ART for children, there are still significant barriers to disclosing HIV to infected children in this setting. There is a need for health care providers to support caregivers to disclose shortly after diagnosis especially in view of the older age of diagnosis among children enrolled in ART program in this setting.
\end{abstract}

Keywords: South Africa; Disclosure; HIV; Children; Caregivers; Antiretroviral Treatment; Family

\section{Introduction}

The 2008 South African national HIV prevalence survey reported an increase in the survival time of adults and children living with HIV coincident with the increased access to antiretroviral therapy (ART) [1]. By the end of 2009, about 86,270 children younger than 15 years of age in South Africa were on ART according to the Joint United Nations Programme on HIV/AIDS estimates [2]. Increasing survival into adolescence of HIV infected children with increased access to ART is reported in studies conducted in well-resourced countries [3-5]. Considering that children infected with HIV are living much longer healthier lives than before, the question of HIV diagnosis disclosure becomes more significant [6-9]. According to Salter-Goldie and colleagues [3], caregivers naturally want to protect their children from complex problems related to HIV disclosure, but as children develop and seek answers about their health, full disclosure becomes necessary. Disclosure is shown to have positive effects on the clinical course of the disease, is related to improved adherence, and enables children to understand HIV infection and make sense of disease related experiences [7,10-18]. Additional reasons for disclosing HIV to infected children, particularly adolescents, are to educate them about preventing the transmission of HIV to their partners through sexual activities [3,12,19].

However, current data from developing countries show that many HIV infected children on ART do not know that they are HIV infected $[6,9,11,15,20,21]$. Data from two South Africa studies on disclosure published to date show that only $9 \%$ of children knew their HIV diagnosis $[22,23]$. Nonetheless, these studies were conducted before the roll out of ART to children in South Africa. Although disclosure has become part of the comprehensive care of HIV infected children in South Africa, caregivers and health care providers continue to struggle with disclosure to HIV infected children till later in adolescence [6,8, 24,25]. The most common reasons for delaying disclosure include; fear of hurting the child, that the child is too 
young to understand, fear that the child will not be able to keep the secret and will be socially rejected and discriminated, fear that disclosure will have negative emotional consequences for the children, and because caregivers believed that they did not know how to tell or how to approach the disclosure process $[5,12,17,26,27]$. Although caregivers often delay disclosure till later age and adolescent, there is no evidence to suggest that disclosure negatively affects HIV-positive children. On the contrary, children who know their HIV diagnosis appear more likely to accept medical care and have higher self-esteem than those who are unaware of their diagnosis $[10,14$, 28,29]. However, the few negative outcomes of disclosure documented, include the family's experience of stigma when children share their diagnosis with others, or an emotional burden for children when they are asked to keep HIV diagnosis a secret [28].

Given the limited data on HIV disclosure to infected children in developing countries, it is not yet clear what factors influence caregivers' communication with their children and others about issues related to the HIV diagnosis disclosure of their children [30]. Previous studies maintained that caregivers often struggle with when and how to disclose the HIV diagnosis to children [19, 31,32]. However, recent data show that caregivers have a range of opinions regarding when the child should be informed and who should be involved in the process, despite most of them having not disclosed to their children [30]. Assessing caregivers' disclosure practices and views are essential to the on-going care of children receiving ART [33]. It is only recently that children living in South Africa, have been receiving ART, and limited data have been published on HIV disclosure to infected children receiving ART. The purpose of this study was to examine the patterns of disclosing the HIV diagnosis to children and family members, and determined the demographic characteristics associated with disclosure.

\section{Methods and Materials}

\subsection{Study Design}

A cross sectional study was conducted with caregivers of children on ART using semi structured interviews. Data were collected between December 2010 and January 2011. A total of 149 caregivers were recruited from the paediatric HIV clinic in Odi district hospital, in North West Province, South Africa. The hospital started with adult ART in 2006 while the paediatric clinic started providing ART to children from surrounding rural villages and informal settlements during the course of 2010. Most of the children who were receiving ART from this clinic were referred from the tertiary hospital in the district as part of the referral of children to access ART in clinics.

At the time of data collection, there were no data yet to indicate how many children were enrolled in the ART programme. Therefore, a census representing a total sample of caregivers of children aged 4 - 17 years was conducted. Caregivers were recruited to participate as they waited for consultation and medication during the routine monthly visits for their children. All caregivers who volunteered to participate in the study were included. For the purpose of this study, we defined a caregiver as the biological mother, biological father, grandmother, grandfather, foster parent, or other relatives who performs primary caregiving functions for the child routinely or on a daily basis.

\subsection{Data Collection}

Structured interviews were conducted using a questionnaire developed in English with inputs from literature on disclosure of HIV to children [19,34]. The questionnaire was developed in English and translated into Setswana, the local language of the caregivers in the study area. The questionnaire was pretested and revised prior to the start of data collection to ensure quality of the data. Caregivers provided socio-demographic information regarding their age, gender, and employment status, level of education, marital status, and relationship with the child as well as their HIV status. In addition, caregivers provided demographic information for the children under their care including age, gender, school grade, diagnosis age, duration on ART, disclosure status, age at disclosure as well as the orphan status of children not cared for by biological parents. The questionnaire also contained openended questions; caregivers of children who had been disclosed to, were asked about who disclosed to the child while caregivers of children who had not been disclosed to were asked about their intention to disclose. All caregivers were asked about disclosure of the child's HIV diagnosis to family members and other people.

\subsection{Data Analysis}

Data were entered into a Microsoft Excel 2003 spread sheet and imported to the Stata version 10.0 [35]. First, descriptive statistics were carried out to explore the socio-demographic characteristics of caregivers and children and the results were summarised as frequencies and percentages. The results for numerical variables were summarised as means and standard deviations. T-test was used to compare means between children who knew their HIV diagnosis and those who did not know. P-values less than or equal to 0.05 were considered to be statistically significant. Responses to open-ended questions were 
quantified and also analysed using Stata version 10.0 [31] and results were summarised as frequencies and percentages.

The Medunsa Research Ethics Committee of the University of Limpopo granted ethical approval for the study, and permission to conduct the study was obtained from the hospital management of Odi hospital. Written informed consent was obtained from caregivers before data collection.

\section{Results}

\subsection{Caregiver Characteristics}

Almost all the caregivers 146 (96.6\%) were female, with a mean age of 42.4 years, $(\mathrm{SD}=14.9$, range $19-81$ years). The main caregivers were biological mothers 78 (52.3\%), followed by grandmothers 42 (28.19\%), and 26 (17.4\%) were other relatives. Half, $76(51.0 \%)$ of the caregivers had a secondary education, more than half 83 (55.7\%) were unemployed, and $21(14.0 \%)$ were pensioners, the majority 64 (42.9\%) were single. Almost half, 71 (47.7\%) of the children were cared for by people other than their biological parents. In addition, data were collected on the caregiver's HIV status, and more than half 89 (59.7\%) of the caregivers were HIV positive, 55 (36.9\%) were HIV negative and 5 (3.36\%) did not know their HIV status. All $78(100 \%)$ of the biological mothers were HIV positive, and about $6(n=36)$ grandmothers were HIV positive.

Chi squared tests (for dichotomous independent variables) were used to examine the association between caregiver demographic characteristics (age, marital status, employment status, level of education, relationship to child, caregiver HIV status, and orphan status) and the disclosure status of the child. The only caregiver characteristic significantly associated with HIV disclosure to children was having a deceased biological father ( $\mathrm{p}$ value $=0.004$ ).

Caregivers' age (p value $=0.182)$, marital status $(\mathrm{p}$ value $=0.582)$, employment status $(p$ value $=0.404)$, educational attainment $(p$ value $=0.724)$, relationship to child ( $\mathrm{p}$ value $=0.293$ ), HIV status ( $\mathrm{p}$ value $=0.172$ ), and whether biological mother was alive or not ( $\mathrm{p}$ value $=$ 0.402 ), were not significantly associated with HIV disclosure to children. Table 1 summarises the caregivers' characteristics of disclosed and not disclosed children.

\subsection{Characteristics of Children}

A total of 149 caregivers provided information on the children under their care. There were slightly more girls $86(57.7 \%)$ than boys $63(42.2 \%)$ in the sample. The mean age of the children was 8.2 years $(\mathrm{SD}=3.1$, range
Table 1. Characteristic of children by HIV disclosure status.

\begin{tabular}{|c|c|c|c|}
\hline \multicolumn{4}{|c|}{ HIV diagnosis disclosed (n) \% } \\
\hline Variables & No $(\mathrm{n}=90)$ & Yes $=(59)$ & p-Value \\
\hline Marital status & & & 0.582 \\
\hline Single & $43(47.8)$ & $21(35.6)$ & \\
\hline Married & $21(23.3)$ & $15(25.4)$ & \\
\hline Live with partner & $11(12.2)$ & $10(17.0)$ & \\
\hline Divorced & $3(3.3)$ & $4(6.9)$ & \\
\hline Widowed & $12(13.3)$ & 9 (15.3) & \\
\hline Employment status & & & 0.404 \\
\hline Employed & $28(31.1)$ & $13(22.0)$ & \\
\hline Unemployed & $49(54.4)$ & $34(57.6)$ & \\
\hline Pensioner & $10(11.1)$ & $11(18.6)$ & \\
\hline Schooling & $3(3)$. & $1(1.6)$ & \\
\hline Highest Level of education & & & 0.724 \\
\hline Primary & $20(22.2)$ & 17 (28.9) & \\
\hline Secondary & $46(51.1)$ & 30 (50.9) & \\
\hline Grade 12 & $21(23.3)$ & $10(17.0)$ & \\
\hline Tertiary & $3(3.3)$ & $2(3.4)$ & \\
\hline Relationship to child & & & 0.293 \\
\hline Mother & $52(57.8)$ & $26(44.1)$ & \\
\hline Father & $2(2.2)$ & $1(1.7)$ & \\
\hline Grand mother & $24(26.7)$ & $18(30.5)$ & \\
\hline Other & $12(13.3)$ & $14(23.7)$ & \\
\hline Caregivers HIV status & & & 0.172 \\
\hline Negative & $29(32.2)$ & $26(44.1)$ & \\
\hline Positive & $59(65.6)$ & 30 (50.9) & \\
\hline Unknown & $2(2.2)$ & $3(5.1)$ & \\
\hline Mother alive $(n=149)$ & & & 0.402 \\
\hline No & $32(35.6)$ & $25(42.4)$ & \\
\hline Yes & $58(64.4)$ & $34(57.6)$ & \\
\hline Father alive ( $n=147$ ) & & & 0.004 \\
\hline No & 19 (21.6) & $25(42.4)$ & \\
\hline Yes & $60(68.2)$ & $24(40.7)$ & \\
\hline Unknown & $9(10.2)$ & $10(16.9)$ & \\
\hline
\end{tabular}

4 - 17 years). All the caregivers provided information on the diagnosis age of the children; the majority 90 (60.4\%) were diagnosed between 1 and 5 years, the mean diagnosis age was 5.3 years $(\mathrm{SD}=3.6)$. All $(100 \%)$ of the children were on ART; the mean time on ART was 3.0 years $(\mathrm{SD}=1.79)$, and the mean age when children started ART was 5.9 years, $(\mathrm{SD}=3.5)$. Caregivers were also asked to indicate whether the biological mother of the child in their care was alive; 57 (38.3\%) of the children 
were maternal orphans, while the father was not alive in 44 (29.9\%) of the cases. More than a third 21 (35.7\%) of the children, who were maternal orphans had lost their fathers too, rendering these children double orphans. Table 2 summarises the characteristics of the disclosed and not disclosed children.

\subsection{Age of Disclosure}

Caregivers reported that 59 (39.6\%) of the children were told their HIV diagnosis. Table 3 summarises the characteristics of disclosed children. Caregivers were asked the age at which the children were informed of their HIV diagnosis. More than half 30 (50.85\%) learned about their HIV diagnosis between 11 and 17 years, 26 (44.1\%) between 6 and 10 years and only 3 (5.1\%) of the children were younger than 6 years when they learned about their HIV diagnosis. The mean age of disclosure was 9.3 years ( $\mathrm{SD}=2.9$, range $4-17$ years). The majority of children 23 (40.4\%) who knew their HIV diagnosis had known for less than a year, the mean time since disclosure was 2.3 years $(\mathrm{SD}=1.3$, range a few months to 5 years). Almost half of the children 29 (49.1\%) were informed of their HIV between 1 - 5 years of their being diagnosed with HIV, the mean time since diagnosis was 2.9 years, ( $\mathrm{SD}=2.6$, range a few months to 10 years).

Table 2. Characteristic of children by HIV disclosure status.

\begin{tabular}{lccc}
\hline \multicolumn{4}{c}{ HIV diagnosis disclosed (n) $\%$} \\
\hline Variables & (No n $=90)$ & Yes $=(59)$ & p-Value \\
Age & $31(34.5)$ & $3(5.8)$ & $<0.01$ \\
4 - 5 yr & $54(60.0)$ & $26(44.1)$ & \\
6 - 10 yr & $5(5.6)$ & $30(50.8)$ & \\
11 - 17 yr & & & $<0.01$ \\
Diagnosis age & $67(74.4)$ & $23(38.9)$ & \\
1 - 5 yr & $23(25.6)$ & $18(30.5)$ & \\
6 - 10 yr & 0 & $18(30.5)$ & \\
$11-17$ yr & & & $<0.01$ \\
Age when ART was initiated & $61(67.8)$ & $15(25.4)$ & \\
1 - 5 yr & $29(32.2)$ & $24(40.7)$ & \\
6 - 10 yr & 0 & $20(33.9)$ & \\
$11-17$ yr & & & 0.430 \\
Duration of ART & $83(92.2)$ & $55(93.2)$ & \\
1 - 5 yr & $7(7.7)$ & $3(5.0)$ & \\
6 - 10 yr & 0 & $1(1.6)$ & \\
11 yr & $19(21.1)$ & $2(3.4)$ & \\
Schooling & $71(78.9)$ & $57(96.6)$ & \\
No & & & \\
Yes & & & \\
\hline
\end{tabular}

Table 3. Characteristics of children who have been disclosed to $(n=59)$.

\begin{tabular}{|c|c|c|}
\hline & Frequency & Percent \\
\hline \multicolumn{3}{|l|}{ Person who disclosed } \\
\hline Mother & 23 & 38.98 \\
\hline Grandmother & 17 & 28.81 \\
\hline Health provider & 13 & 22.03 \\
\hline Other relatives & 5 & 8.47 \\
\hline Father & 1 & 1.69 \\
\hline \multicolumn{3}{|l|}{ Age at disclosure } \\
\hline$>6$ years & 6 & 10.2 \\
\hline $6-10$ years & 31 & 52.5 \\
\hline $11-17$ years & 22 & 37.3 \\
\hline Mean disclose age & \multicolumn{2}{|c|}{9.3 years } \\
\hline \multicolumn{3}{|l|}{ Time since disclosure } \\
\hline$>1$ year & 23 & 40.4 \\
\hline 1 year & 9 & 15.8 \\
\hline 2 years & 14 & 24.6 \\
\hline 3 years & 9 & 15.8 \\
\hline 4 years & 1 & 1.8 \\
\hline 5 years & 1 & 1.8 \\
\hline Mean disclose time & \multicolumn{2}{|c|}{2.3 years } \\
\hline \multicolumn{3}{|l|}{ Time since diagnosis } \\
\hline$>1$ year & 25 & 42.4 \\
\hline 1 - 5 years & 29 & 49.1 \\
\hline $6-10$ years & 5 & 8.5 \\
\hline Mean diagnosis time & \multicolumn{2}{|c|}{2.9 years } \\
\hline
\end{tabular}

T-tests (for continuous independent variables) were used to compare the means of children who knew their HIV diagnosis and children who did not know. Children who knew their HIV diagnosis were older than those who did not know, mean age of 10.6 vs 6.7 years p value < 0.01 . Pearson Chi-squared tests were used to compare characteristics of children who knew their HIV diagnosis with those who did not know. The characteristics of the children that were significantly associated with HIV disclosure were the age of the child ( $\mathrm{p}$ value $<0.01$ ), diagnosis age (p value $<0.01$ ), age when ART was initiated ( $p$ value $<0.01$ ), disclosed age ( $p$ value $<0.01$ ) schooling ( $\mathrm{p}$ value $<0.01$ ). Duration of ART (p value $=0.430$ ) was not significantly associated with HIV disclosure. Children were more likely to know their HIV diagnosis if they were older, were diagnosed at an older age, were at an older age when the ART was initiated, and were in school. 


\subsection{Persons Who Informed Children of Their Diagnosis}

For the majority 23 (39\%) of children, disclosure was done by their biological mothers, almost a third 17 (29\%) were disclosed to by grandparents; about a quarter 13 (22\%) by health care providers (health providers were doctors, nurses and social workers) and almost a tenth 5 (8.5\%) by other relatives. The "other relatives" were older siblings, aunts, and uncles who played the role of informal foster parents.

Fisher's exact tests were used to examine the association between disclosed caregiver demographic characteristics, (marital status, employment status, level of education, and relationship to child, caregiver HIV status, and orphan status, and the disclosure status of the child). Caregiver characteristics significantly associated with persons who discloses HIV to children were if the caregiver was single ( $\mathrm{p}$ value $=0.002$ ), had a primary education $(\mathrm{p}$ value $=0.051)$ was unemployed $(\mathrm{p}$ value $<0.01)$ and was the biological mother of the child ( $\mathrm{p}$ value $<$ $0.01)$.

\subsection{Disclosure of the Child's HIV Diagnosis to Others}

All the caregivers responded to open ended questions about the other people they disclosed the HIV diagnosis of the child to, as well as the reasons for disclosing to these people. Although two thirds (60\%) of the caregivers had not disclosed the HIV diagnosis to their children, almost all 143 (99.3\%) said that other members of their family knew about the child's HIV diagnosis. Almost all 137 (95.8\%) of those who knew were the grandparents of the child, siblings of the parents or caregivers and other extended family members. Only 5 (3.5\%) caregivers told the older siblings of the HIV-infected child about the HIV diagnosis. In almost all the cases, family members were disclosed the HIV diagnosis of the child before disclosure to the child occurred.

Caregivers gave several reasons for disclosing the child's HIV diagnosis to other people, Table 4 show the reasons for disclosing the child's HIV diagnosis to family members. Some of the reasons cited include; that the child was sick; that previous exposure to HIV in the family resulted in the signs of HIV/AIDS related illness becoming apparent to family members; that they disclosed so the family could assist in caring for the child; that they depend on the family for financial and emotional support; that they disclosed to ensure that the child would be taken care of, and the family will ensure that the child adheres to medication in the event of the death of the caregiver. There were also incidences were disclosure was unintended, and the family found out accidentally
Table 4. Caregiver's reasons for disclosing the child's HIV diagnosis to family members.

\begin{tabular}{|c|c|}
\hline Caregiver responses & Freq. \\
\hline $\begin{array}{l}\text { The caregiver depends on family members for financial } \\
\text { and emotional support. }\end{array}$ & 44 \\
\hline $\begin{array}{l}\text { So that the family should assist in caring for the child as } \\
\text { well as to ensure that the child adhere to medication. }\end{array}$ & 73 \\
\hline $\begin{array}{l}\text { To protect the family from accidental HIV infection when } \\
\text { they care for the child. }\end{array}$ & 14 \\
\hline $\begin{array}{l}\text { The child was sickly and the family was asking questions } \\
\text { about the child's illness and encouraged the parent to have } \\
\text { the child tested. }\end{array}$ & 25 \\
\hline $\begin{array}{l}\text { The caregiver did not want to keep secrets from the family } \\
\text { and thought disclosure was the right thing to do. }\end{array}$ & 16 \\
\hline Disclosure was accidental or unintended. & 22 \\
\hline $\begin{array}{l}\text { The caregiver believed that the family would keep the } \\
\text { diagnosis secret. }\end{array}$ & 3 \\
\hline $\begin{array}{l}\text { The family has been exposed to HIV previously and } \\
\text { HIV/AIDs related signs were becoming obvious. }\end{array}$ & 15 \\
\hline $\begin{array}{l}\text { To ensure that the child is cared for in case the caregiver } \\
\text { dies. }\end{array}$ & 11 \\
\hline
\end{tabular}

from the clinic when they accompanied the caregiver and child to the hospital for routine follow up.

\subsection{Intention to Disclose}

Caregivers who had not disclosed the HIV diagnosis to their children were asked about their future intention to disclose. All the caregivers acknowledged that they should inform their children about their HIV diagnosis in the future. Caregivers were also asked about their thoughts on the most appropriate time they intent to disclose the HIV diagnosis to their children. A quarter 22 (24.7\%) planned to disclose to the child between 6 and 9 years, slightly more than one quarter 24 (27\%) planned to disclose when the child is 10 years, $13(14.6 \%)$ would disclose when the child is 12 years, 15 (16.9\%) would disclose to the child between 13 and 18 years. The mean intended age for disclosure was 8.9 years $(\mathrm{SD}=4.5$, range 4 - 17 years).

The caregivers were also asked about the person who will inform the child of his/her HIV diagnosis. More than half $50(55.5 \%)$ thought that the mother should be the one to disclose the HIV diagnosis to the child, one quarter $23(25.6 \%)$ thought that the grandmother should disclose, and only $6(6.7 \%)$ thought that a health care provider should be responsible for disclosure. The majority of biological mothers, 46 (88.5\%) thought that they should disclose themselves. Table 5 summarises care- 
givers’ responses regarding their intentions to disclose.

\section{Discussion}

This study examined the patterns of HIV diagnosis disclosure to infected children and family members. Caregivers reported that $39.6 \%$ of the children knew their HIV diagnosis. For the majority of children (38.9\%), disclosure was done by the biological mothers; about a third of the children were disclosed to by their grandmothers, and a quarter was disclosed to by health care providers. Although the majority of the children were informed of the HIV diagnosis by their biological mothers, more than two thirds (61\%) of the children were actually disclosed to by people other than their biological parents. The current study findings are consistent with other studies showing that caregivers who disclose early tend to be caregivers who are not biological parents of the infected children [4,13,16,36,37]. Disclosure is especially difficult for HIV infected biological parents who might be particularly worried about their children learning of their illness given the stigma associated with the disease, as well as the methods of transmission [6]. Furthermore, HIV infected biological parents may feel responsible and guilty for infecting the children and fear that their children may blame them [3,4,18,36,37].

Table 5. Caregiver responses regarding future intentions to disclose the HIV diagnosis to children.

\begin{tabular}{|c|c|c|}
\hline Variables & Frequency & Percentage \\
\hline \multicolumn{3}{|c|}{ Appropriate time to disclose } \\
\hline 6 - 9 years & 22 & 24.7 \\
\hline 10 years & 24 & 27.0 \\
\hline 11 years & 2 & 2.3 \\
\hline 12 years & 13 & 14.6 \\
\hline 13 - 18 years & 15 & 16.9 \\
\hline Unsure & 13 & 14.6 \\
\hline Mean age & \multicolumn{2}{|c|}{8.9 years } \\
\hline \multicolumn{3}{|c|}{ Person responsible for disclosure } \\
\hline Mother & 50 & 55.6 \\
\hline Grand mother & 23 & 25.6 \\
\hline Other relatives & 7 & 7.8 \\
\hline Health care providers & 6 & 6.7 \\
\hline Parents & 2 & 2.2 \\
\hline Father & 1 & 1.1 \\
\hline Grand father & 1 & 1.1 \\
\hline
\end{tabular}

Of the children who learned about their HIV diagnosis from persons other than their biological mothers (61\%), almost a third was informed by their grandmothers. In this study, $38.3 \%$ of the children were maternal orphans and almost two thirds of these children were cared for by their grandmothers. However, less than half (42.8\%) of the children cared for by their grandmothers were informed of their HIV diagnosis. The findings suggest that disclosure was difficult even when the caregivers are grandparents who as is the case with biological mothers, are often subjected to the social stigma associated with HIV [6]. Caregiver characteristics significantly associated with HIV disclosure to children were if the caregiver was single, had a primary education, was unemployed and was the biological mother of the child. We found that there were similarities between the characteristics of caregivers who had disclosed and caregivers who intend to disclose. In response to who should inform the child of their HIV diagnosis, the majority of caregivers who intend to disclose felt that the child's mother/parents and the grandmother were the best persons to eventually disclose to the child. These data lend support to previous studies indicating that caregivers desire to be the primary persons to disclose the HIV diagnosis to their children. Almost half of the caregivers in studies conducted in Congo, India, and Thailand, reported that they would like to be the ones who disclose the HIV diagnosis to their children [17,30,38,39].

Consistent with findings from other studies [9,40], a quarter of the children was informed of their HIV diagnosis by health care providers. The data show an increased involvement of health care providers in disclosing HIV to children than previously reported in South Africa [23,24], and other settings [8,21]. The caregiver's need to be supported in the disclosure discussion by health care providers have been previously reported [12, $17,19,21,23]$. However, support from health care providers is never meant to make the caregiver less responsible for disclosure. In spite of the need for support, the caregivers would like to be the ones to make the decisions of when the child should be informed of the HIV diagnosis. In this study, less than a tenth of the caregivers felt that a health care provider should be responsible for disclosure.

There are some differences in the current study findings when compared to other studies, for instance in Ethiopia, Congo, and Uganda, the majority of caregivers felt that a health care provider should be responsible for HIV disclosure to children [6,8,30]. While in Thailand, about half of the caregivers needed to be supported by healthcare providers to inform the child about the diagnosis [17]. It is worth noting that almost all non-disclosed caregivers in this study were of the opinion that the child should be informed about their diagnosis, and 
that almost all intend to do so, even though the majority continued to delay disclosure. Similar findings were reported in previous studies [30,41]. According to BoonYasidhi and colleaques [41], most caregivers realized that they should disclose the HIV diagnosis to their children but were often not ready to do so. Vaz and colleagues [30]. Argue that although caregivers want to play the main role in the disclosure of HIV to the child, most may not feel capable to do so. Caregiver's lack of skills on how to disclose HIV to infected children has been previously reported $[8,31,42,43]$.

Similar to previous studies [15,17,30,37], older child age was found to be a determining factor for disclosure of HIV diagnosis to children. Though the actual age of disclosure might vary across studies, the prevalence of disclosure increases with increasing age of the child [30]. In this study, more than third of the children learned of their HIV diagnosis between 11 and 16 years, and the mean age of disclosed children was 10.6 years as compared to 6.7 years for non-disclosed children. There was a significant difference between the mean age of disclosed and non-disclosed children ( $\mathrm{p}$ value $<0.001$ ). The data support findings from previous studies indicating that very few children less than 6 years of age know their HIV diagnosis [30,37]. In this study, only six children were younger than 6 years when they learned of their HIV diagnosis. Children in this study were more likely to know their HIV diagnosis if they were older, were diagnosed at an older age, were at an older age when ART was initiated and were in school. Although the duration on ART was not statistically significant with disclosure, given that children are diagnosed around the mean age of 5.3 years, and it takes an average of 2.9 years for caregivers to disclose after HIV diagnosis, it is therefore, unlikely that children younger than 6 years would know their HIV diagnosis in this setting.

The mean age of disclosure (9.3 years) is comparable to other studies [15,23], but much lower than the mean age of 13.6 and 15 years reported in Congo and Thailand $[9,17]$. Previously, Kallem and colleagues suggested that increased access to ART in resource limited settings would result in rapid decline in age at disclosure [15] which might explain the lower age of disclosure observed in this study. There was no statistical difference between the mean age of children who knew their HIV diagnosis and the intended mean age of disclosure (9.3 vs 8.9). Slightly more than half of the caregivers who intended to disclose thought that the most appropriate time to disclose was when the child was between 6 and 10 years. This age category is consistent with the age of disclosure observed in this study; slightly more than half of the children were informed of their HIV diagnosis between 6 and 10 years. The study further found that more than a third of the caregivers thought that the appropriate time to disclose was when the child was older than 10 years i.e. between 11 and 18 years. The intended age of disclosure is in line with the pattern of disclosure observed in the study. More than a third of the children were informed of their HIV diagnosis between 11 and 16 years.

However, there seems to be a lack of consensus and knowledge regarding the appropriate age for disclosure in this study and others $[6,17,37,38]$. Findings from the current study show that some of the non-disclosed caregivers were not sure about the appropriate time to tell children of their HIV diagnosis. Data show that the appropriate age of disclosure from studies conducted in developing and well developed countries vary (range 11 16 years) $[6,17,37,38]$, but the majority of caregivers in developing countries felt that the child should be told about their HIV diagnosis around 14 years $[6,17,38]$. The older intended age of disclosure observed in this study and others suggest that despite increased access to ART for children in developing countries, there are still significant barriers to disclosing the HIV diagnosis to children.

Regarding disclosure of the child's HIV diagnosis to other people, almost all the caregivers reported that other members of their family knew about the child's HIV diagnosis. Those who knew were the grandparents of the child, siblings of the parents or caregivers and other extended family members like aunts and uncles. Similar findings were reported elsewhere [33]. Siblings of the infected children were the least people who were informed about the HIV diagnosis of the infected child; only five caregivers reported that the siblings of the HIV infected child were told about the diagnosis. In all the five cases, the informed siblings were older than the infected child. Hejoaka [44] maintains that siblings of an infected child are often told about the diagnosis in the case of single parent families headed by mothers. This was also the case in this study. In almost all the cases, the family members in this study were told about the HIV diagnosis of the child long before disclosure to the child occurred. Similar findings were reported in other settings $[9,45]$.

Data from previous studies show that disclosing a child's HIV diagnosis to other people could result in benefits for shared childcare $[33,46,47]$. Similarly, caregivers in this study disclosed so that the family could assist in caring for the child as well as ensuring that the child adheres to the ART medication. Caregivers also disclosed because they depended on their immediate and often extended family members for financial and emotionally support. The dependency on the family should be viewed in the context were almost two thirds of the care- 
givers were unemployed, and their only source of income was the child support grant they received. These data support previous findings which suggest that disclosure to others allows caregivers to receive support in maintaining ART adherence for the child [33]. There were also cases in this study where disclosure was inevitable because of previous exposure of the family to HIV and AIDS. Some of the caregivers reported that the child was sickly, and that signs of HIV related illness became obvious to other family members. In other cases, the biological mother of the child died from AIDS related infections and the family could make the connection when the child became sick. Fundamental to the reasons for disclosing the child's HIV diagnosis to the family was in preparation for the biological parent's pending death. Biological parents disclosed the HIV diagnosis of the child to ensure that the child would be taken care of in the event of the death of the parent.

There is an increase in the prevalence of disclosure to children on ART as well as low mean age of disclosure among children in this study. Age remains the most predictor of HIV disclosure as well as a predictor of the intention to disclose the HIV diagnosis to children. While biological caregivers desire to be the persons who inform the child of their HIV diagnosis, the majority of children who knew their HIV diagnosis were informed of the diagnosis by people other than their biological mothers. A relatively high proportion of the children were informed of their HIV diagnosis by health care providers. In general, caregivers took about 3 years after the initial HIV diagnosis to disclose to their children. On the other hand, disclosure of the child's HIV diagnosis to family members happened immediately after the child's HIV diagnosis. Caregivers disclosed to family members they depended on emotionally and or financially. Non-disclosed caregivers view disclosing the HIV diagnosis to children as inevitable, and the majority intend to disclose in the future. There was however, lack of consensus and knowledge regarding the appropriate age for disclosing the HIV diagnosis to children.

Health care providers should support caregivers in disclosure so that children are informed of their HIV shortly after diagnosis especially in view of the older age of diagnosis among children enrolled in ART programs in this and other settings. The caregiver's expressed need to be supported in the disclosure discussion by health care providers offers an opportunity for the greater involvement of health care providers in disclosing the HIV diagnosis to children in this setting. It is imperative that health care providers have the appropriate training and skill to understand disclosure issues and develop culture sensitive interventions to support care choosing to disclose the HIV diagnosis to the children. Furthermore, health care providers will need to take into consideration the changing needs of the increasing numbers of adolescents living with HIV infection and intensify prevention efforts for HIV to prevent HIV transmission from teen to teen. Therefore disclosure should be incorporated into regular discussions between health care providers and caregivers of HIV-infected children and adolescents.

\section{Acknowledgements}

The study was funded by the Directorate General for Development Cooperation (DGDC) through the Flemish Interuniversity council (VLIR-UOS). The author thanks Ms J Mahloko and Mr Nick Maubane, for data collection. We also thank health care providers from the paediatric clinic of Odi hospital for their guidance and assistance during data collection.

\section{REFERENCES}

[1] O. Shisana, T. Rehle, L. C. Simbayi, K. Zuma, J. Jooste, et al., "South African National HIV Prevalence, Incidence, Behaviour and Communication Survey 2008: A Turning Tide among Teenagers?” HSRC Press, Cape Town, 2009. http://www.hsrc.ac.za/Document-3239.phtml

[2] UNAIDS, "Report on the Global AIDS Epidemic," UNAIDS, Geneva, 2009.

http://www.unaids.org/en/dataanalysis/epidemiology/200 9aidsepidemicupdate/

[3] R. Salter-Goldie, S. M. King, M. L. Smith, A. Bitnun, J. Brophy, et al., "Disclosing HIV Diagnosis to Infected Children: A Health Care Team's Approach,” Vulnerable Children and Youth Studies: An International Interdisciplinary Journal for Research, Policy and Care, Vol. 2, No. 1, 2007, pp. 12-16.

[4] C. Thorne, M. L. Newell, F. A. Botet, A. B. Bohlin, A. Ferrazin, et al., "Older Children and Adolescents Surviving with Vertically Acquired HIV Infection,” Journal of Acquired Immune Deficiency Syndromes, Vol. 29, No. 4, 2002, pp. 396-401.

[5] L. P. Wiener, C. A. P. Mellins, S. P. Marhefka and H. B. P. Battles, "Disclosure of an HIV Diagnosis to Children: History, Current Research, and Future Directions," Journal of Developmental \& Behavioral Pediatrics, Vol. 28, No. 2, 2007, pp. 155-166. doi:10.1097/01.DBP.0000267570.87564.cd

[6] S. Biadgilign, A. Deribew and A. E. H. K. D. Amberbir, "Factors Associated with HIV/AIDS Diagnostic Disclosure to HIV Infected Children Receiving HAART: A MultiCenter Study in Addis Ababa, Ethiopia,” PLoS One, Vol. 6, No. 3, 2011, Article ID: e17572. doi:10.1371/journal.pone.0017572

[7] M. Ferris, K. Burau, A. M. Schweitzer, S. Mihale, N. Murray, et al., "The Influence of Disclosure of HIV Diagnosis on Time to Disease Progression in a Cohort of Romanian Children and Teens," AIDS Care: Psychological and Socio-Medical Aspects of AIDS/HIV, Vol. 19, No. 
9, 2007, pp. 1088-1094.

[8] J. Rujumba, C. Mbasaalaki-Mwaka and G. Ndeezi, “Challenges Faced by Health Workers in Providing Counselling Services to HIV-Positive Children in Uganda: A Descriptive Study," Journal of the International AIDS Society, Vol. 13, No. 1, 2010, p. 9. doi:10.1186/1758-2652-13-9

[9] L. Vaz, A. Corneli, J. Dulyx, S. Rennie, S. Omba, et al., "The Process of HIV Status Disclosure to HIV-Positive Youth in Kinshasa, Democratic Republic of the Congo," AIDS Care: Psychological and Socio-Medical Aspects of AIDS/HIV, Vol. 20, No. 7, 2007, pp. 842-852.

[10] P. J. Bachanas, K. A. Kullgren, K. S. Schwartz, B. Lanier, J. S. McDaniel, et al., "Predictors of Psychological Adjustment in School-Age Children Infected with HIV," Journal of Pediatric Psychology, Vol. 26, No. 6, 2001, pp. 343-352. doi:10.1093/jpepsy/26.6.343

[11] W. Bikaako-Kajura, E. Luyirika, D. W. Purcell, J. Downing, F. Kaharuza, et al., "Disclosure of HIV Status and Adherence to Daily Drug Regimens among HIV-Infected Children in Uganda," AIDS and Behavior, Vol. 10, 2006, pp. 85-93. doi:10.1007/s10461-006-9141-3

[12] I. Blasini, C. Chantry, C. Cruz, L. Ortiz, I. Salabarría, et al., "Disclosure Model for Pediatric Patients Living with HIV in Puerto Rico: Design, Implementation, and Evaluation," Journal of Developmental \& Behavioral Pediatrics, Vol. 25, No. 3, 2004, pp. 181-189. doi:10.1097/00004703-200406000-00007

[13] L. Chi-Ling and R. Johann-Liang, "Disclosure of the Diagnosis of HIV/AIDS to Children Born of HIV-Infected Mothers," AIDS Patient Care and STDs, Vol. 13, No. 1, 1999, pp. 41-45. doi:10.1089/apc.1999.13.41

[14] I. Funck-Brentano, D. Costagliola, N. Seibel, E. Straub, M. Tardieu, et al., "Patterns of Disclosure and Perceptions of the Human Immunodeficiency Virus in Infected Elementary School-age Children," Archives of Pediatric Adolescence Medicine, Vol. 151, No. 10, 1997, pp. 978985. doi:10.1001/archpedi.1997.02170470012002

[15] S. Kallem, L. Renner, M. Ghebremichael and E. Paintsil, "Prevalence and Pattern of Disclosure of HIV Status in HIV-Infected Children in Ghana," AIDS and Behavior, Vol. 15, No. 6, 2010, pp. 1121-1127. doi:10.1007/s10461-010-9741-9

[16] A. Lesch, L. Swartz, A. Kagee, K. Moodley, Z. Kafaar, et al., "Paediatric HIV/AIDS Disclosure: Towards a Developmental and Process-Oriented Approach,” AIDS Care: Psychological and Socio-Medical Aspects of AIDS/HIV, Vol. 19, No. 6, 2007, pp. 811-816.

[17] P. Oberdorfer, T. Puthanakit, O. Louthrenoo, C. Charnsil, V. Sirisanthana, et al., "Disclosure of HIVAIDS Diagnosis to HIV-Infected Children in Thailand," Journal of Paediatrics and Child Health, Vol. 42, No. 5, 2006, pp. 283-288. doi:10.1111/j.1440-1754.2006.00855.x

[18] S. Waugh, "Parental Views on Disclosure of Diagnosis to Their HIV-Positive Children,” AIDS Care: Psychological and Socio-Medical Aspects of AIDS/HIV, Vol. 15, No. 2, 2003, pp. 169-176.
[19] D. Dematteo, C. Harrison, C. Arneson, R. S. Goldie, A. Lefebvre, et al. "Disclosing HIV/AIDS to Children: The Paths Families Take to Truth Telling," Psychology, Health \& Medicine, Vol. 7, No. 3, 2002, pp. 339-356. doi:10.1080/13548500220139395

[20] S. Biadgilign, A. Deribew, A. Amberbir and K. Deribe, "Barriers and Facilitators to Antiretroviral Medication Adherence among HIV-Infected Paediatric Patients in Ethiopia: A Qualitative Study,” Journal of Social Aspects of HIV/AIDS Research Alliance/SAHARA, Human Sciences Research Council, Vol. 6, No. 4, 2009, pp. 148154.

[21] L. M. E. Vaz, E. Eng, S Maman, T. Tshikandu and F. Behets, "Telling Children They Have HIV: Lessons Learned from Findings of a Qualitative Study in SubSaharan Africa,” AIDS Patient Care and STDs, Vol. 24, No. 4, 2010, pp. 247-256. doi:10.1089/apc.2009.0217

[22] F. G. Kouyoumdjian, T. Meyers and S. Mtshizana, "Barriers to Disclosure to Children with HIV," Journal of Tropical Pediatric, Vol. 51, No. 5, 2005, pp. 285-287. doi:10.1093/tropej/fmi014

[23] K. Moodley, L. Myer, D. Michaels and M. Cotton, "Paediatric HIV Disclosure in South Africa; Caregivers' Perspectives on Discussing HIV with Infected Children," South African Medical Journal, Vol. 96, No. 3, 2006, pp. 201-204.

[24] L. Myer, K. Moodley, F. Hendricks and M. Cotton, “Healthcare Providers' Perspectives on Discussing HIV Status with Infected Children,” Journal of Tropical Pediatric, Vol. 52, No. 4, 2006, pp. 293-295.

[25] E. K. Santamaria, C. Dolezal, S. L. Marhefka, S. Hoffman, Y. Ahmed, et al., "Psychosocial Implications of HIV Serostatus Disclosure to Youth with Perinatally Acquired HIV,” AIDS Patient Care and STDs, Vol. 25, No. 4, 2011, pp. 257-264. doi:10.1089/apc.2010.0161

[26] S. Instone, "Perceptions of Children with HIV Infection When Not Told for So Long: Implications for Diagnosis Disclosure," Journal of Pediatric Health Care, Vol. 14, No. 5, 2000, pp. 235-243.

[27] W. M. Nehring, F. R. Lashley and K. Malm, "Disclosing the Diagnosis of Pediatric HIV Infection: Mothers' Views,” Journal for Specialists in Pediatric Nursing, Vol. 5, No. 1, 2000, pp. 5-14. doi:10.1111/j.1744-6155.2000.tb00081.x

[28] C. E. Abadía-Barrero and M. D. LaRusso, "The Disclosure Model versus a Developmental Illness Experience Model for Children and Adolescents Living with HIV/ AIDS in São Paulo, Brazil," AIDS Patient Care and STDs, Vol. 20, No. 1, 2006, pp. 36-43.

[29] P. Lester, M. Chesney, M. Cooke, R. Weiss, P. Whalley, et al., "When the Time Comes to Talk about HIV: Factors Associated with Diagnostic Disclosure and Emotional Distress in HIV-Infected Children," Journal of Acquired Immune Deficiency Syndromes, Vol. 31, No. 3, 2002, pp. 309-317. doi:10.1097/00126334-200211010-00006

[30] L. M. E. Vaz, S. Maman, E. Eng, O. A. Barbarin, T. Tshikandu, et al., "Patterns of Disclosure of HIV Status 
to Infected Children in a Sub-Saharan African Setting,” Journal of Developmental \& Behavioral Pediatrics, Vol. 32, No. 4, 2011, pp. 307-315. doi:10.1097/DBP.0b013e31820f7a47

[31] G. J. Domek, "Debunking Common Barriers to Pediatric HIV Disclosure,” Journal of Tropical Pediatric, Vol. 56, No. 6, 2010, pp. 440-442. doi:10.1093/tropej/fmq013

[32] T. P. Nelms and V. L. Zeigler, “A Study to Develop a Disclosure to Children Intervention for HIV-Infected Women," Journal of the Association of Nurses in AIDS Care, Vol. 19, No. 6, 2008, pp. 461-469. doi:10.1016/j.jana.2008.05.005

[33] R. C. Vreeman, W. M. Nyandiko, S. O. Ayaya, E. G. Walumbe, D. G. Marrero, et al., "Factors Sustaining Pediatric Adherence to Antiretroviral Therapy in Western Kenya," Qualitative Health Research, Vol. 19, No. 12, 2009, pp. 1716-1729. doi:10.1177/1049732309353047

[34] S. W. Ledlie, "Diagnosis Disclosure by Family Caregivers to Children Who Have Perinatally Acquired HIV Disease: When the Time Comes,” PhD Thesis, University of Pennsylvania, Philadelphia, 1998.

[35] StataCorp., "Stata Statistical Software, Release 10," StataCorp LP, College Station, 2007.

[36] S. W. Ledlie, "Diagnosis Disclosure by Family Caregivers to Children Who Have Perinatally Acquired HIV Disease: When the Time Comes," Nursing Research, Vol. 48, No. 3, 1999, pp. 141-149. doi:10.1097/00006199-199905000-00004

[37] C. A. Mellins, E. Brackis-Cott, C. Dolezal, A. Richards, S. W. Nicholas, et al., "Patterns of HIV Status Disclosure to Perinatally HIV-Infected Children and Subsequent Mental Health Outcomes," Clinical Child Psychology and Psychiatry, Vol. 7, No. 1, 2002, pp. 101-114. doi: $10.1177 / 1359104502007001008$

[38] S. Arun, A. Singh, R. Lodha and S. Kabra, "Disclosure of the HIV Infection Status in Children," Indian Journal of Pediatrics, Vol. 76, No. 8, 2009, pp. 805-808. doi:10.1007/s12098-009-0177-z

[39] A. Siripong, T. Bunupuradah, W. Apateerapong, P. Boonrak, C. Pancharoen, et al., "Attitudes of Thai Care- givers of Children with HIV Infection towards HIV Disclosure," Vulnerable Children and Youth Studies: An International Interdisciplinary Journal for Research, Policy and Care, Vol. 2, No. 3, 2007, pp. 191-197.

[40] C. Merzel, N. Van Devanter and M. Irvine, “Adherence to Antiretroviral Therapy among Older Children and Adolescents with HIV: A Qualitative Study of Psychosocial Contexts,” AIDS Patient Care and STDs, Vol. 22, No. 12, 2008, pp. 977-987. doi:10.1089/apc.2008.0048

[41] V. Boon-Yasidhi, U. Kottapat, Y. Durier, N. Plipat, W. Phongsamart, et al., "Diagnosis Disclosure in HIV-Infected Thai Children,” Journal of Medical Association of Thailand, Vol. 88, Suppl. 8, 2005, pp. S100-S105.

[42] Nöstlinger, T. Jonckheer, E. de Belder, E. van Wijngaerden, C. Wylock, et al., "Families Affected by HIV: Parents' and Children's Characteristics and Disclosure to the Children," AIDS Care: Psychological and Socio-Medical Aspects of AIDS/HIV, Vol. 16, No. 5, 2004, pp. 641-648.

[43] J. Rwemisisi, B. Wolff, A. Coutinho, H. Grosskurth, J. Whitworth, “'What If They Ask How I Got It?' Dilemmas of Disclosing Parental HIV Status and Testing Children for HIV in Uganda," Health Policy Plan, Vol. 23, No. 1, 2008, pp. 36-42. doi:10.1093/heapol/czm040

[44] F. Hejoaka, "Care and Secrecy: Being a Mother of Children Living with HIV in Burkina Faso,” Social Science \& Medicine, Vol. 69, No. 6, 2009, pp. 869-876. doi:10.1016/j.socscimed.2009.05.041

[45] P. Lester, M. Chesney, M. Cooke, P. Whalley, B. Perez, et al., "Diagnostic Disclosure to HIV-Infected Children: How Parents Decide When and What to Tell," Clinical Child Psychology and Psychiatry, Vol. 7, No. 1, 2002, pp. 85-99. doi:10.1177/1359104502007001007

[46] F. Hejoaka, "HIV Disclosure to Children in Low-Resource Countries: A Forgotten Issue on the International AIDS Policy Agenda,” AIDS 2008, 17th International AIDS Conferences, Mexico City, 3-8 August 2008.

[47] A. R. Moore and Williamson, “Disclosure of Children's Positive Serostatus to Family and Nonfamily Members: Informal Caregivers in Togo, West Africa,” AIDS Research and Treatment, 2011, Article ID: 595301. 